\title{
Salat Dhuha Improves Haemodynamic: A Randomized Controlled Study
}

Elman Boy ${ }^{1,2 *} \mathbb{D}$, Aznan Lelo ${ }^{3}$, Amira Permatasari Tarigan ${ }^{4}$, Yetty Machrina ${ }^{5}$, Yusni Yusni ${ }^{6}$, Juliandi Harahap ${ }^{7}$, Rosita Juwita Sembiring $^{8}$, Santi Syafril ${ }^{9}$, Gusbakti Rusip ${ }^{10}$, Cindy Azzahra Freeman ${ }^{11}$

${ }^{1}$ Faculty of Medicine, Universitas Sumatera Utara, Medan, Indonesia; ${ }^{2}$ Department of Public Health, Faculty of Medicine, Universitas Muhammadiyah Sumatera Utara, Medan, Indonesia; ${ }^{3}$ Department of Medicine and Therapeutics, Faculty of Medicine, Universitas Sumatera Utara, Medan, Indonesia; ${ }^{4}$ Department of Pulmonology, Faculty of Medicine, Universitas Sumatera Utara, Medan, Indonesia; ${ }^{5}$ Department of Physiology, Faculty of Medicine, Universitas Sumatera Utara, Medan, Indonesia; ${ }^{6}$ Department of Physiology, Faculty of Medicine, Universitas Syiah Kuala, Aceh, Indonesia; ${ }^{7}$ Department of Public Health, Faculty of Medicine, Universitas Sumatera Utara, Medan, Indonesia; ${ }^{8}$ Department of Clinical Pathology, Faculty of Medicine, Universitas Sumatera Utara, Medan, Indonesia; ${ }^{9}$ Department of Internal Medicine, Faculty of Medicine, Universitas Sumatera Utara, Medan, Indonesia; ${ }^{10}$ Department of Physiology, Faculty of Medicine, Universitas Muhammadiyah Sumatera Utara, Medan, Indonesia; ${ }^{11}$ Faculty of Medicine, Universitas Muhammadiyah Sumatera Utara, Medan, Indonesia

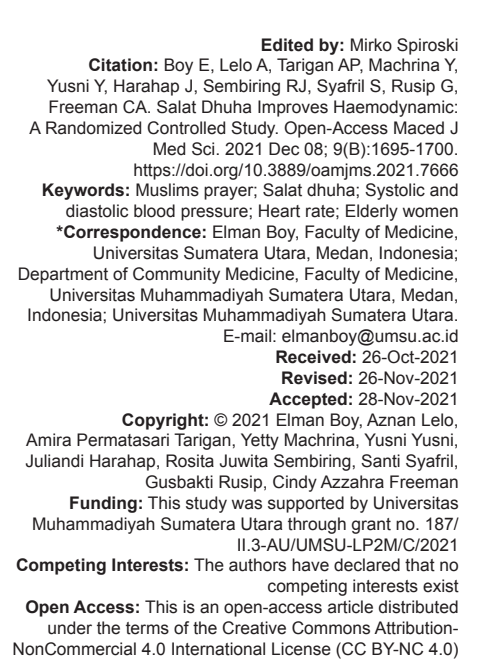

Introduction

The prevalence of hypertension increases with age, more than 1 in every two elderly have hypertension, dominated by women [1]. Furthermore, COVID-19 has had the negative impact on hemodynamic outcomes through the "domino effect," initiated by social distancing and safety issues. Due to concerns of joining fitness facilities, elders may not be attend for exercise. Lack of physical activity due to home quarantine can increase the rate of hypertension in the elderly [2]. Stress triggers a physiological response in the sympathetic nerve system, which increases hemodynamic parameters. Therefore, it is important for the elderly to manage

\begin{abstract}
BACKGROUND: The prevalence of hypertension increases with age, more than 1 in every two elderly have hypertension, dominated by women. The primary prevention of hypertension is a worldwide public health concern Salat Dhuha is a moderate-inte
improved hemodynamic in adults.

AIM: Our study purpose was to asses the effects of 2 and 8 rakaats of Salat Dhuha in improving systolic and diastolic blood pressure and heart rate in healthy elderly women. study. We completed a formal physical, clinical, and blood assessments before admission. Participants with a history of hypertension were excluded from the study. The participants were randomized into 2 groups, i.e., "8 rakaats group" $(n=13)$ and "2 rakaats group" $(n=13)$ of Salat Dhuha. Two participants dropped out from the present study. were statistically analyzed.

RESULTS: Both groups demonstrated the benefits of Salat Dhuha in improving hemodynamic parameters (systolic and diastolic blood pressure and heart rate). However, the reduction of systolic blood pressure in the "2 rakaats
group" $(2.16 \mathrm{mmHg}$ ) was less than in the "8 rakaats group" $(5.50 \mathrm{mmHg})$, the reduction of diastolic blood pressure in the "2 rakaats group" $(0.75 \mathrm{mmHg})$ was less than the "8 rakaats group" $(2.41 \mathrm{mmHg})$ and the reduction of heart rate in "2 rakaats group" $(2.08 \mathrm{bpm})$ was less than the "8 rakaats group" (6.08 bpm). All differences were statistically significant $(p<0.05)$.
\end{abstract}

CONCLUSION: This study demonstrated that the Salat Dhuha has a significant potential in improving hemodynamic parameters for elderly women which the more frequent rakaat will give more benefit than less frequent rakaat. their stress levels, by including the use of spiritual approaches to manage blood pressure [3].

The primary prevention of hypertension is a worldwide public health concern. This provides an opportunity to prevent the costly cycle of managing hypertension and its complications [4]. The primary prevention of hypertension using the mind-body medicine has greatly improved in recent years. This increase has been accelerated by the development in medical technologies such as brain imaging [5].

Salat Dhuha is physical activity with moderate intensity [6]. Salat Dhuha is a physical and psychological activity as well as inducing parasympathetic nerve activity and suppressing sympathetic nerve activity 
through the release of brain alpha waves [7]. The Salat Dhuha consists of certain repeated postures called rakaat [8]. Salat Dhuha is derived from the Arabic language meaning the morning prayer, which is performed by Muslim congregations, consisting of several different postures including standing, bowing, prostration and sitting [9].

A previous cross-sectional study has reported the effect of performing two rakaats of actual Salat practice on blood pressure compared to mimic Salat practice as measured using an Electrocardiograph and Automatic Blood Pressure Monitor. The results showed that systolic and diastolic blood pressure decreased significantly after actual Salat practice compared to mimic Salat practice [10]. However, changes in blood pressure and heart rate in the number of rakaat of Salat have not been studied. This study aims to determine changes in systolic and diastolic blood pressure and heart rate after performing the 2 and 8 rakaats of Salat Dhuha.

\section{Materials and Methods}

\section{Study population}

The study was conducted in December 2020 to September 2021, followed by 101 elderly women who were at the Senior Care Residence Binjai (Figure 1). All participants gave consent to participate in this study after being explained about the procedures and potential risks of the study, in accordance with the 1964 Declaration of Helsinki. The volunteers were informed that they could withdraw from the experiment at any time.

Demographic characteristics of volunteers were obtained through questionnaires, including whether they routinely perform Salat Dhuha or not; if they do it regularly, how they do it (e.g., sitting in a chair or upright due to standard practice); and how many rakaat of Salat Dhuha they do regularly. Detailed physical examination and several blood tests (cholesterol, hemoglobin, and blood glucose) were performed on all volunteers. Volunteers who regularly perform Salat Dhuha in a standard position (standing), free from cardiovascular, metabolic, and other diseases were included in this study.

Twenty-six elderly Muslim female volunteers aged between 60 and 74 years who met the study criteria were randomly divided into two groups by a lottery paper as follows: Thirteen volunteers who chose number 2 were put into "2 rakaats group" and thirteen other volunteers who chose number 8 put into the " 8 rakaats group."

\section{Material}

The materials used in this study were Omron automatic blood pressure measuring device, model:
HEM-7130 (automatic oscillometric blood pressure device) [11], made in Japan, with adult cuff size; digital weight Serenity 150, model: SR-DS 11, made in Indonesia; General Care meter stature $2 \mathrm{M}$, made in Jiangsu Suhong Medical Instrument Co.Ltd; Blood glucose, cholesterol, and hemoglobin test strip and meter, Easy Touch GCHB 3 in 1, made in Taiwan.

\section{Procedures}

This study was conducted with a controlled prospective study design. Measurements of systolic and diastolic blood pressure and heart rate were carried out before and after the 6-week intervention. The research protocol has been approved by the Ethics Committee of the Universitas Sumatera Utara (USU) (Code of Ethics 776/ KEP/USU/2020), recommended by the local government (recommendation number: 070-028/BKB.P///2021), and has received permission from the authorized government (permited number: 423.4/D140/DINSOS-U///2021).

\section{Salat dhuha}

All volunteers have been invited to attend Salat Dhuha in the mosque. Salat Dhuha was performed in congregation, led by an imam who is registered at the Senior Care Residence. Salat Dhuha was performed at least 5 times a week, for 6 weeks, between 08.00 and 10.00 am. Volunteers in the "8 rakaats group" had performed prayer in the first row (behind the imam), while the "2 rakaats group" were prayed in the second row (behind the "8 rakaats group").

Each rakaat of Salat Dhuha consists of 7-9 different postures [12]. During the Salat Dhuha, all worshipers must recite some verses of the Quran (by moving their lips) [13]. Each rakaat started in a standing position, then the hands were raised up to ear level (takbir) and lowered one by one by holding the left wrist with the right hand on the chest (qiyam) for 60-90 s. Then, bowing (rukuk) for 5-10 s, performed with forward movement of the spine, especially at the lumbar joints, supported with both hands straight gripping the hyperextended knee. Then, the worshipper stood again (iktidal) for 3-5 s. Afterwards, they moved from a standing position to prostration, placing their forehead on the ground, with the palms still at ears level, and touch the ground with bent elbows for 5-10 s. Then they sit for 3-5 s, with the left and right knees in a bent position for 3-5 s, then the prostration was repeated (the second prostration was identical with the first). The first rakaat was completed [14].

Then the worshipers stand again to start the second rakaat. They stop in the qiyam position for $60-90 \mathrm{~s}$, then bowed for 5-10 s (the posture is the same as bowing in the first rakaat). Then iktidal for 3-5 s, after that prostration (the posture was the same as prostration in the first rakaat) for $5-10 \mathrm{~s}$, and sitting 
(the posture was identical to sitting in the first rakaat) for 3-5 s. Then prostrate again for 5-10 s. Next, sit on the left knee flexed with inverted ankle dorsiflexed and flexed of the right knee and metatarsophalangeal joint for 60-75 s. Then, the cycle ends by looking at the right shoulder once and the left shoulder once, while offering greetings [15].

\section{Blood pressure and heart rate}

Participants were asked to avoid smoking and consuming caffeinated products such as coffee, cola or tea, at least 30 min before measuring blood pressure and heart rate. Each volunteer sat in a chair for $5 \mathrm{~min}$ before blood pressure was recorded. The cuff is attached to the upper left arm. When measuring blood pressure and heart rate, neither the participant nor the examiner was allowed to speak [16].

\section{Data analysis}

Data obtained were statistically analyzed. The Shapiro-Wilk test was conducted to determine the distribution of the data. The baseline systolic blood pressure data were not normally distributed, but the baseline characteristics of other volunteers, diastolic blood pressure, and heart rate were normally distributed. Independent t-test was performed to analyze the differences of mean and standard deviation of diastolic blood pressure and heart rate between the two groups, while the systolic blood pressure between the two groups was analyzed by Mann-Whitney test. Paired sample t-test was performed to analyze the difference in mean and standard deviation of pre-post intervention of diastolic blood pressure and heart rate in each group, while the Wilcoxon test was performed to analyze systolic blood pressure. All statistical tests used a two-tailed test and the level of acceptance of statistical significance ( $p$ value) was at least 0.05 .

\section{Results}

\section{Baseline characteristics}

Twenty-six volunteers were recruited and randomly divided into two equal numbers for the "2 rakaats group" and "8 rakaats group." The number of volunteers who dropped out was the same in both groups, citing a reluctance to perform Salat Dhuha regularly and due to fever for several days. Twenty-four volunteers (12 from the "2 rakaats group" and 12 from the "8 rakaats group") completed the study. The basic characteristics of volunteers who completed the study were homogeneous (there was no difference between the two groups) in the number of rakaat of Salat Dhuha routinely performed, age, cholesterol levels, blood sugar levels, hemoglobin levels, systolic and diastolic blood pressure, and heart rate (Table 1).

Table 1: Baseline characteristics (adjusted)

\begin{tabular}{|c|c|c|c|}
\hline \multirow[t]{3}{*}{ Feature } & \multicolumn{2}{|c|}{ Group Salat Dhuha } & \multirow[t]{3}{*}{$\mathrm{p}$} \\
\hline & 2 Rakaats & 8 Rakaats & \\
\hline & Mean $\pm S D$ & Mean $\pm S D$ & \\
\hline Perform dhuha regularly (rakaat) & $2.17 \pm 5.77$ & 2 & $0.31^{\mathrm{b}}$ \\
\hline Age (year) & $68.08 \pm 3.80$ & $68.58 \pm 4.62$ & $0.77^{\mathrm{b}}$ \\
\hline Height $(\mathrm{cm})$ & $147.92 \pm 4.94$ & $150.50 \pm 4.05$ & $0.17^{\mathrm{a}}$ \\
\hline Weight $(\mathrm{Kg})$ & $48.64 \pm 5.55$ & $46.72 \pm 4.41$ & $0.35^{\mathrm{b}}$ \\
\hline $\mathrm{BMI}\left(\mathrm{kg} / \mathrm{m}^{2}\right)$ & $22.23 \pm 2.63$ & $20.65 \pm 2.08$ & $0.11^{\mathrm{a}}$ \\
\hline Cholesterol (mg/dL) & $158 \pm 32.90$ & $172 \pm 25.77$ & $0.25^{\mathrm{a}}$ \\
\hline Blood Glucose 1-2 h PP (mg/dL) & $112 \pm 19.40$ & $118 \pm 20.37$ & $0.50^{\mathrm{a}}$ \\
\hline Haemoglobin ( $\mathrm{g} / \mathrm{dL}$ ) & $13.12 \pm 1.52$ & $13.20 \pm 1.27$ & $0.88^{\mathrm{a}}$ \\
\hline
\end{tabular}

\section{6 weeks after intervention}

\section{Systolic blood pressure}

At the 6-week follow-up, systolic blood pressure decreased significantly in both groups ( $p<0.05$ ), but in the "8 rakaats group," systolic blood pressure fell 3 times lower than in the "2 rakaats group" (4, 31\% vs. $1.68 \%$ ) (Table 2 ).

Table 2. Mean differences changes of hemodynamic parameters (adjusted)

\begin{tabular}{|c|c|c|c|}
\hline \multirow[t]{3}{*}{ Feature } & \multicolumn{2}{|c|}{ Group Salat Dhuha } & \multirow{3}{*}{$\begin{array}{l}p \text { value for comparison } \\
\text { between } 2 \text { groups }\end{array}$} \\
\hline & 2 Rakaats & 8 Rakaats & \\
\hline & Mean \pm SD & Mean $\pm S D$ & \\
\hline \multicolumn{4}{|l|}{ Systolic $(\mathrm{mmHg})$} \\
\hline Before & $128.75 \pm 4.11$ & $127.25 \pm 7.5$ & $0.55^{\mathrm{b}}$ \\
\hline After & $126.58 \pm 4.70$ & $122 \pm 70$ & $0.06^{\mathrm{a}}$ \\
\hline $\begin{array}{l}\mathrm{p} \text { value for comparison } \\
\text { between before and after } \\
\text { in each group }\end{array}$ & $0.01^{\mathrm{d} *}$ & $0.01^{\mathrm{d} *}$ & \\
\hline \multicolumn{4}{|l|}{ Diastolic (mmHg) } \\
\hline Before & $78.08 \pm 7.42$ & $77.83 \pm 7.15$ & $0.93^{\mathrm{a}}$ \\
\hline After & $77.33 \pm 69$ & $75.42 \pm 70$ & $0.50^{\mathrm{a}}$ \\
\hline $\begin{array}{l}\mathrm{p} \text { value for comparison } \\
\text { between before and after } \\
\text { in each group }\end{array}$ & $0.03^{\mathrm{c} *}$ & $0.01^{\mathrm{c} *}$ & \\
\hline \multicolumn{4}{|l|}{ Heart Rate (time/minute) } \\
\hline Before & $80.08 \pm 4.56$ & $83.92 \pm 10.51$ & $0.25^{\mathrm{a}}$ \\
\hline After & $78 \pm 4.39$ & $77.83 \pm 10.7$ & $0.96^{\mathrm{a}}$ \\
\hline $\begin{array}{l}p \text { value for comparison } \\
\text { between before and after } \\
\text { in each group }\end{array}$ & $0.01^{\mathrm{c*}}$ & $0.01^{\text {c* }}$ & \\
\hline
\end{tabular}

\section{Diastolic blood pressure}

At the 6-week follow-up, diastolic blood pressure decreased significantly in both groups ( $p<0.05)$, but in the " 8 rakaats group," the diastolic blood pressure fell almost 3 times lower than the "2 rakaats group" (3 0.08\% vs. 0.96\%) (Table 2).

\section{Heart rate}

At the 6-week follow-up, heart rate decreased significantly in both groups $(p<0.05)$, but in the "8 rakaats group," the heart rate decreased by 2 times lower than in the "2 rakaats group" (7.14 \% vs. $2.59 \%)$ (Table 2). 


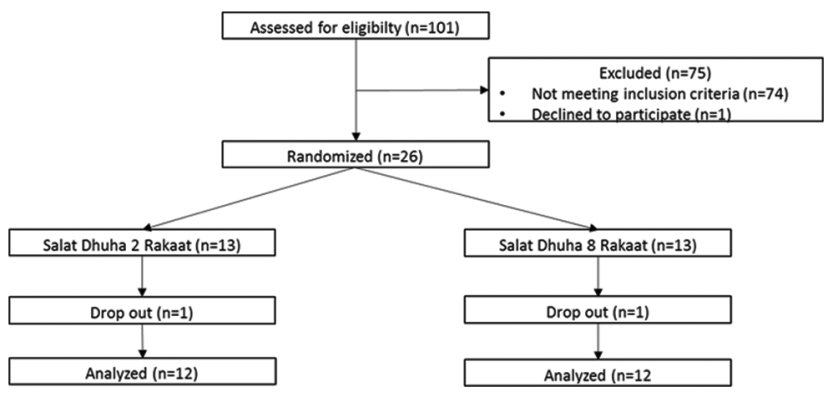

Figure 1: Consort flow diagram

\section{Discussion}

This is the first study to examine the effectivity of mind-body medicine based on one of the Islamic practices, namely Salat Dhuha performed for 6 weeks on blood pressure and heart rate among elderly women. Subjects recruited in this study were healthy volunteers and with homogeneous characteristics in both groups (Table 1). Although, blood pressure and heart rate decreased significantly in both groups of Salat Dhuha, "8 rakaats group" appeared to be more effective in lowering blood pressure and heart rate than "2 rakaats group" (Fig. 2).

Until now, research on the effect of prayer on blood pressure and heart rate is still very limited. Salat Dhuha postures are consimilar poses to yoga, which is a mental, physical and spiritual practice initiated by the ancient Indians to achieve a stable state of peace [6]. Yoga practice is not effective in reducing hemodynamic parameters in the adult population with comorbidities. Tillin et al., (2019) have demonstrated the effect of Yoga on patients aged 35-80 years with cardiac rehabilitation, myocardial infarction, and Percutaneous Coronary Intervention performed for 3 months. Although they found that yoga could reduce systolic blood pressure
(1 $\mathrm{mmHg})$, diastolic blood pressure $(1 \mathrm{mmHg})$, and heart rate $(1 \mathrm{bpm})$, but the decrease in hemodynamic parameters were not significant $(p>0.05)$ [17]. Meanwhile, in this recent study, all hemodynamic parameters (systolic and diastolic blood pressure and heart rate) decreased significantly after 6 weeks (a period of $1 \frac{1}{2}$ months) duration of intervention. It is interesting to note that this study showed a greater improvement in hemodynamic parameters compared to the Tillin et al., study, i.e., systolic $(5.5 \mathrm{mmHg}$ vs. $1 \mathrm{mmHg}$ ), diastolic $(2.41 \mathrm{mmHg}$ vs. $1 \mathrm{mmHg}$ ), and heart rate (4 bpm vs. $1 \mathrm{bpm})$.

In a previous cross-sectional study, 2 rakaats of actual praying had a better effect to lowering resting blood pressure than the group that only imitated prayer movements. Doufesh et al., (2013), have shown the effect of praying 2 rakaats on healthy young adult man (20-30 years). They found that the actual prayer had significantly lower blood pressure compared to the group that imitated the prayer, ie., systolic ( $3 \mathrm{mmHg}$ vs. $2 \mathrm{mmHg}$ ) and diastolic (2 $\mathrm{mmHg}$ vs. $1 \mathrm{mmHg}$ ) [10]. It is interesting to note that Doufesh's et al., research shows that imitating prayer provides almost the same blood pressure-lowering effect as Tillin's study, i.e., systolic (2 $\mathrm{mm} \mathrm{Hg}$ vs. $1 \mathrm{~mm} \mathrm{Hg}$ ) and diastolic (1 $\mathrm{mm} \mathrm{Hg}$ vs. $1 \mathrm{~mm} \mathrm{Hg}$ ), whereas the actual Salat practice showed greater improvement in hemodynamic parameters than the results of the Tillin et al. study, ie., systolic $(3 \mathrm{mmHg}$ vs. $1 \mathrm{mmHg}$ ) and diastolic (2 $\mathrm{mmHg}$ vs. $1 \mathrm{mmHg}$ ). Salat is a total obedience way to worship God among Muslims [18]. Blood circulation also increases during prayer. During actual prayer differences in posture and prayer recitation during prayer increase blood circulation to the face and tongue due to sensory and motor activity responses [18]. These two things play an important role in improving hemodynamic parameters due to prayer. The present study showed that the more rakaat of Salat Dhuha is done, the better the results are in hemodynamic changes.

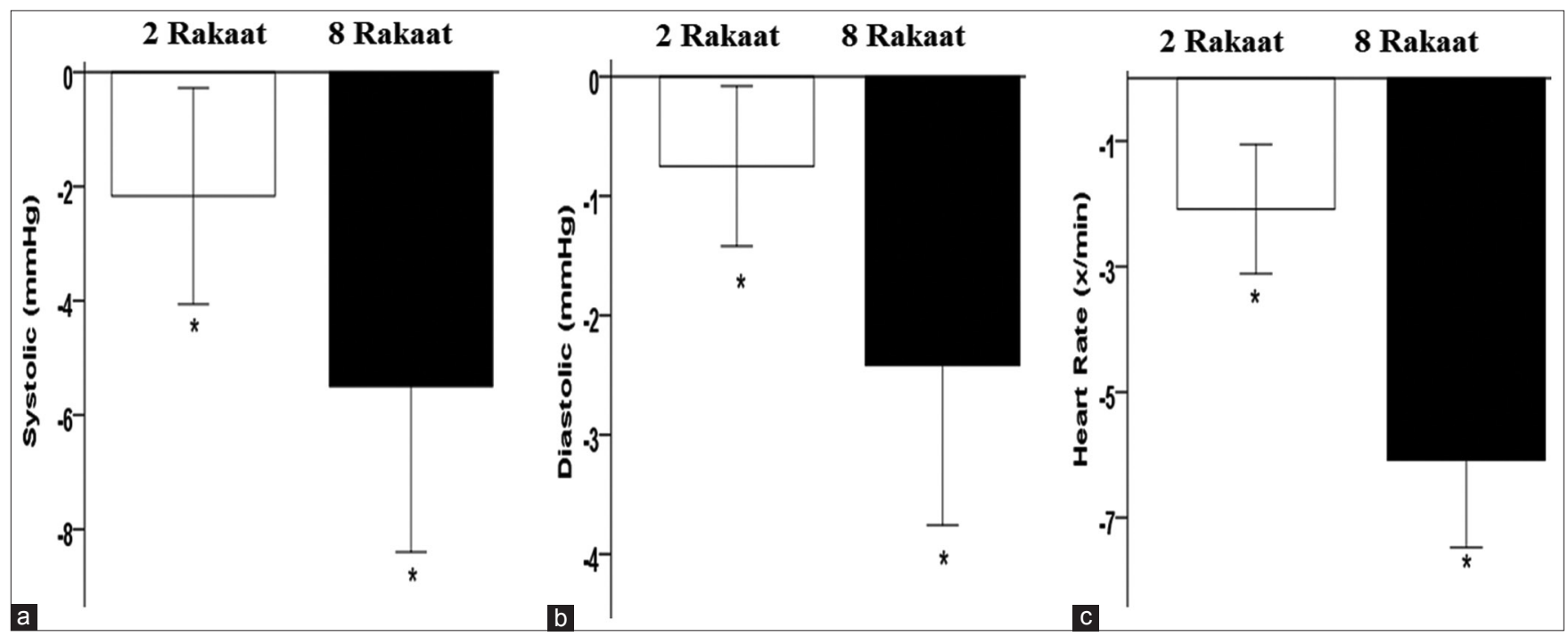

Figure 2: Mean differences changes of haemodynamic features level. systolic blood presure (a), diastolic blood presure (b), heart rate (c), were measured for each group after-before of study. Values are expressed as the mean \pm standard deviation; ${ }^{*} p<0.05$. 
Therefore, it is reasonable that the improvement of hemodynamic parameters in the 8 rakaats of Salat Dhuha is more significant than two rakaats. Decreases in systolic and diastolic blood pressure and heart rate may also be related to the role of Salat on joint flexibility and muscle endurance, through repeated changes in posture. Movement in Salat trains various muscles and joints to perform a series of repetitive activities that are in accordance with ergonomics [15]. During Salat, all joints and muscles are involved in physical activity which in turn plays an important role in cerebral blood flow and postural reflexes. Two rakaats of Salat Dhuha form 14 postures, while eight rakaats form 56 postures. The difference in prayer postures of the both groups was 42 postures per prayer session. During the study, each volunteer was asked to attend 30 sessions of Dhuha prayer, so the difference in the number of postures between the two groups during the present study was 1,260 postures.

Based on the results obtain from this study, the more the number of rakaat of Salat Dhuha performed by elderly women, the better the haemodynamic parameters produced. This happens because Salat Dhuha triggers the activity of the parasympathetic nerve system. Although in the early stages of prayer, sympathetic nerve activity increases, i.e. increases heart rate (encouraging blood circulation to meet the body's oxygen needs) [19], but in later stages, prayer increases parasympathetic activity through the release of relative waves of alpha power (RPA) in the brain [7]. Therefore, physiological changes of parasympathetic nerve system activity are thought to also induce gastrointestinal and urinary tract motility. These two physiological parameters (frequent defecation and urination) will be studied in the next Salat Dhuha research.

Salat Dhuha is one of the Islamic religious practices [20]. Previous studies have shown that prayer improves relaxation, concentration, and balance the state of the human mind-body system [12]. This is in line with other study that reported a direct relationship between salat and the power of gamma waves in the human brain during actual Salat practice compared mimic Salat practice. In actual Salat practice, it shows significantly higher mean gamma power in all brain regions, except the middle parietal region in the sitting position, and the front area in the bow position. This enhancement in gamma power during Salat strengthen the concept of Salat as meditation that can increase focused attention [21], [22], [23], [24].

Another factor that can be related to the results of the present study is the role of prayer in suppresion of expression of matrix metalloproteins (MMP) 2 and 9. MMP 2 and MMP 9 are responsible for the degradation of vascular elastic fibers [25]. Light-moderate intensity physical activity can reduce elastin fragmentation in the aortic wall by decreasing the expression of MMP 2 and 9. A study by Green, et al., (2017) showed that physical activity is associated with vascular remodeling. Functional and structural adaptations of arteries due to blood movement resulting from repeated exposure to physical activity can increase human hemodynamic forces, luminal shear stress, arterial pressure, and tangential wall pressure, all of which alter arterial function, diameter, and arterial vascular wall thickness [26]. However, these parameters were not measured in this present study. Therefore, the effect of Salat Dhuha on MMP 2 and 9 needs to be investigated further.

No side effects were reported in this study. Although this study has presented the benefits of Salat Dhuha on hemodynamic parameters, the results are still limited to 6 weeks post-intervention. In the future, it is important to conduct research on the effect of Dhuha Prayer on hypertensive patients as a potential secondary treatment in hypertensive patients.

\section{Conclusion}

Two rakaats and eight rakaats of Salat Dhuha for 6 weeks could improve hemodynamics in elderly muslim women.

\section{References}

1. Kementrian Kesehatan Republik Indonesia. Hasil Utama Rise Kesehatan Dasar. Indonesia: Kementrian Kesehatan Republik Indonesia; 2018.

2. Ferdinand KC, Vo TN, Echols MR. State-of-the-art review: Hypertension practice guidelines in the era of COVID-19. Am J Prev Cardiol. 2020;2:100038. https://doi.org/10.1016/j. ajpc.2020.100038 PMid:32835351

3. Park $\mathrm{SH}$, Han KS. Blood pressure response to meditation and yoga: A systematic review and meta-analysis. J Altern Complement Med. 2017;23(9):685-95. https://doi.org/10.1089/ acm.2016.0234

PMid:28384004

4. Satterfield S. Primary prevention of hypertension. J Tenn Med Assoc. 1995;88(7):273-4.

PMid:7658694

5. Saniotis A. Understanding mind/body medicine from muslim religious practices of salat and dhikr. J Relig Health. 2018;57(3):849-57. https://doi.org/10.1007/s10943-014-9992-2 PMid:25613191

6. Bhat RA. Unity of health through yoga and islamic prayer-salah. Acad Sport Sch. 2014;3(10):1-6. Available from: https://www. researchgate.net/profile/raof-bhat/publication/293821675 unity_of_health_through_yoga_and_islamic_prayer_salah'/ links/56bc343108ae47fa3956cc33/unity-of-health-throughyoga-and-islamic-prayer-salah.pdf. [Last accessed on 2021 
Sep 24].

7. Doufesh H, Ibrahim F, Ismail NA, Wan Ahmad WA. Aplication of self organizing map for correlation hunting between alpha band power of EEG signals and other physiological parameters during muslim prayer (Salat). Biomed Eng Appl Basis Commun. 2018;30(4):1850029. Available from: https://www.worldscientific. com. [Last accessed on 2021 Sep 20].

8. Obunadike C. Salat. In: Best "New" African Poets 2018 Anthology. Chitungwiza, Zimbabwe: Mwanaka Media and Publishing; 2018. p. 36-7. Available from: http://www.jstor.org/ stable/10.2307/j.ctvh9vtn3.15. [Last accessed on 2021 Sep 18].

9. Koubaa A, Ammar A, Benjdira B, Al-Hadid A, Kawaf B, Al-Yahri SA, et al. Activity monitoring of Islamic prayer (salat) postures using deep learning. Proceedings of the $20206^{\text {th }}$ Conference on Data Science and Machine Learning Applications CDMA; 2020. p. 106-11.

10. Doufesh H, Ibrahim F, Ismail NA, Ahmad WA. Assessment of heart rates and blood pressure in different salat positions. J Phys Ther Sci. 2013;25(2):211-4. Available from: https://www. jstage.jst.go.jp/article/jpts/25/2/25_jpts-2012-323/_article. [Last accessed 2021 on Sep 18].

11. MattuGS,PerryTL,WrightJM.Comparison oftheoscillometricblood pressure monitor (BPM-100Beta) with the auscultatory mercury sphygmomanometer. Blood Press Monit. 2001;6(3):153-9. https:// doi.org/10.1097/00126097-200106000-00007

PMid:11518839

12. Ghous M, Malik AN, Amjad MI, Kanwal M. Effects of activity repetition training with salat (prayer) versus task oriented training on functional outcomes of stroke. J Pak Med Assoc. 2017;67(7):1091-3.

PMid:28770893

13. Ibrahim F, Sian TC, Shanggar K, Razack AH. Muslim prayer movements as an alternative therapy in the treatment of erectile dysfunction: A preliminary study. J Phys Ther Sci. 2013;25(9):1087-91. https://doi.org/10.1589/jpts.25.1087 PMid:24259921

14. Ibrahim F, Ahmad SA. Assessment of upper body muscle activity during salat and stretching exercise: A pilot study. In: Proceedings of 2012 IEEE-EMBS International Conference on Biomedical and Health Informatics. New Jersey, United States: IEEE; 2012. p. 412-5. Available from: http://www.ieeexplore. ieee.org/document/6211603. [Last accessed 2021 on Sep 18].

15. Aqlan F, Ahmed A, Cao W, Khasawneh MT. An ergonomic study of body motions during Muslim prayer using digital human modelling. Int J Ind Syst Eng. 2017;5(3):79-96.

16. Huang T, Larsen KT, Ried-Larsen M, Møller NC, Andersen LB. The effects of physical activity and exercise on brain-derived neurotrophic factor in healthy humans: A review. Scand J Med
Sci Sports. 2014;24(1):1-10. https://doi.org/10.1111/sms.12069 PMid:23600729

17. Tillin T, Tuson C, Sowa B, Chattopadhyay K, Sattar N, Welsh P, et al. Yoga and cardiovascular health trial (YACHT): A UK-based randomised mechanistic study of a yoga intervention plus usual care versus usual care alone following an acute coronary event. BMJ Open. 2019;9(11):e030119. https://doi.org/10.1136/ bmjopen-2019-030119

PMid:31685500

18. Ghorbani A, Moosavi SA. The effect of prostration (sajda) on cerebral blood flow velocity. J Rafsanjan Univ Med Sci. 2007;6(4):49-54. Available from: http://www.eprints.rums.ac.ir/ id/eprint/6178. [Last accessed on 2021 Sep 18].

19. Doufesh H, Ibrahim F, Ismail NA, Wan Ahmad WA. Effect of muslim prayer (salat) on $\alpha$ electroencephalography and its relationship with autonomic nerve system activity. J Altern Complement Med. 2014;20(7):558-62. https://doi.org/10.1089/ acm.2013.0426

PMid:24827587

20. Afifah N. Salat duha sebagai budaya populer. Religia 2017;20(2):170-3. Available from: http://www.e-journal. iainpekalongan.ac.id/index.php/religia/article/view/927/1224. [Last accessed on 2021 Sep 18].

21. Doufesh H, Faisal T, Lim KS, Ibrahim F. EEG spectra analysis on muslim prayers. Appl Psychophysiol Biofeedback. 2012;37(1):11-8. https://doi.org/10.1007/s10484-011-9170-1 PMid:21965118

22. Osama M, Malik RJ. Salat (Muslim prayer) as a therapeutic exercise. J Pak Med Assoc. 2019;69(3):399-404 PMid:30890834

23. Larasati AN, Boy $E$. The impact of physical activity in elderly Magna Med Berk IIm Kedokt Kesehat. 2020;6(2):113.

24. Doufesh H, Ibrahim F, Safari M. Effects of muslims praying (Salat) on EEG gamma activity. Complement Ther Clin Pract. 2016;24:6-10. https://doi.org/10.1016/j.ctcp.2016.04.004 PMid:27502795

25. Sugimoto $\mathrm{K}$, Nakamura T, Tokunaga T, Uehara $\mathrm{Y}$, Okada $\mathrm{T}$, Taniwaki $\mathrm{T}$, et al. Matrix metalloproteinase promotes elastic fiber degradation in ligamentum flavum degeneration. PLoS One. 2018;13(8):e0200872. https://doi.org/10.1371/journal. pone.0200872

PMid:30067795

26. Green DJ, Hopman MTE, Padilla J, Laughlin MH, Thijssen DH. Vascular adaptation to exercise in humans: Role of haemodynamic stimuli. Physiol Rev. 2017;97(2):495-528. https://doi.org/10.1152/physrev.00014.2016

PMid:28151424 